\title{
What Hindu Sati Can Teach Us about the Sociocultural and Social Psychological Dynamics of Suicide
}

\author{
Seth Abrutyn \\ University of British Columbia
}

\section{Published in Journal for the Theory of Social Behaviour}

\begin{abstract}
By leveraging the case of Hindu sati, this paper elucidates the ways in which structure and culture condition suicidal behavior by way of social psychological and emotional dynamics. Conventionally, sati falls under Durkheim's discussion of altruistic suicides, or the self-sacrifice of underindividuated or excessively integrated peoples like widows in traditional societies. In light of the fact that Durkheim's interpretation was based on uneven data, nineteenth century Eurocentric beliefs, and a theoretical framework that can no longer resist modification and elaboration, by reconsidering sati it is possible to sketch a new model that strengthens Durkheim's theory by making it more robust and generalizable. The following model is built on five principles. First, integration and regulation are not distinct causal forces, but overlapping contextual conditions. Second, to better explain the variation in suicidality across time and space, we must also pay attention to culture as it provides the underlying meanings of suicide that can increase the odds a person or class of persons become suicidal or are protected against suicidality. Third, structure still matters, but in many cases, the role power and powerdifferentials play must be considered. Fourth, understanding why and how people choose suicide depends on incorporating identity and status processes. Fifth, because the expression of social emotions like shame are patterned by structural and cultural conditions, to understand how suicidality is socioculturally patterned we must further explore the link between identity/status, social emotions, and structure and culture.
\end{abstract}

Keywords: Durkheim; Suicide; Hindu Sati; social psychology; theory; cultural sociology; shame 


\section{INTRODUCTION}

Durkheim's Suicide endures today because its principles appear to have empirical efficacy and because it exemplifies the power of the sociological imagination. All too often, however, Suicide serves as a template for publication, as contemporary sociologists apply new data and/or new statistical strategies to test and retest his concrete nineteenth century hypotheses (Wray, Colen and Pescosolido 2011). There is much to be said for replication in science, but the conventional adherence to a century old text has led sociology to a crossroads of sorts. On the one hand, besides a few "pioneers" pushing the frontiers of suicide scholarship (Pescosolido 1994; Abrutyn and Mueller 2014b; Barbagli 2015; Abrutyn and Mueller 2016; Mueller and Abrutyn 2016), sociology has seemingly accepted, wholesale, Durkheim's claims to explaining suicide. Since 1980, Stack and Bowman (2012) report psychiatry has produced over 9000 articles on suicide while sociology has produced 180. In some ways, Durkheim's theoretical model is considered settled, and taught as such in classical theory courses (Collins 1988). In other ways, the pressure to publish often leads quantitative scholars to "take up" the Durkheimian question, taking for granted the theory's "rightness" in favor of sophisticated measurement (Wray et al. 2011). On the other hand, sociologists have more conceptual tools at their disposal and much more latitude in synthesizing them in ways that chart new paths for future research. Thus, questions Durkheim and his orthodox followers have historically failed to answer, such as how and why do suicides spread dyadically, have begun to receive sophisticated theoretical and methodological treatment (Pescosolido and Georgianna 1989; Maimon and Kuhl 2008; Baller and Richardson 2009; Abrutyn and Mueller 2014a; Mueller and Abrutyn 2015). Yet, many questions have only begun to receive systematic attention, particularly in regards to excessive integration and regulation (Pescosolido 1994; Abrutyn and Mueller 2016; Mueller and Abrutyn 2016). 
The paper below expands on Durkheim's discussion of sati as a form of (obligatory) altruistic suicide in order to explicitly focus on processes of excessive integration and regulation This case is of interest because it not only reveals the limits of taking Durkheim too literally but it also underscores the potential for extending and elaborating the Durkheimian theory of suicide. In terms of the limits, we are faced with a case that was clearly viewed through Eurocentric eyes; a perspective that relied upon "ethnographic" reports produced by missionaries, government officials, and merchants/tourists; and, like many of Durkheim's anecdotal cases, one that seemed stereotypic rather than analytically rigorous. In terms of its promise, this paper raises a number of key points. First, it rejects Durkheim's assertion that integration and regulation lead to distinct suicide types; and while Bearman (1991) provides an elegant statement of their interrelationship, sati demonstrates how retaining the typology is problematic. Second, and closely related, sati exemplifies why excessive integration or regulation, as Abrutyn and Mueller (2016) have argued, are not causal mechanisms but rather contextual features of collectives and places. Ultimately, if we accept these two points, then we are forced to reimagine the causal mechanisms driving suicide. Third, the case of sati allows us to not only build on the on-going project of considering the role culture plays in suicide (cf. Hjemeland 2010; Kitanaka 2012; Chua 2014), but also explain the ways in which culture becomes consequential by focusing on the social psychological processes influencing suicidal behaviors

The following paper begins with a brief elucidation of Durkheim's Suicide. Next, it provides a descriptive discussion of the practice of sati, Durkheim's interpretation of sati and a criticism of this interpretation, and, finally, a new explanatory framework. The paper concludes with a discussion of the implications this specific case holds for studying suicides like it and, more generally, for the sociology of suicide. 


\section{DURKHEIM'S SUICIDE}

Durkheim (1897 [1951]) explored suicide with the express goal of establishing sociology as a legitimate discipline by challenging the widespread belief that suicide was a psychological phenomenon. He posited that by looking at suicide rates we could uncover invisible social forces shaping the stable pattern of suicide across various contexts, explain the variation between nation-states and within them across various classes of people (e.g., marital status or religious affiliation), and account for sudden changes in rates. Two principles undergird his argument: the structure of suicide rates is a function of the structure of social relationships and the structure of social relationships vary according to integration or regulation. Using multivariate statistical analysis when possible, Durkheim described three "types" of suicide: egoism (too little integration), altruism (too much integration), and anomic (too little regulation); in a brief footnote (p. 276), he would add, for symmetry, a fourth type, fatalistic suicide (too much regulation). It was his opinion that modern, urban, democratic societies were vulnerable to egoism and anomie because of emergent structural conditions, while traditional societies were at risk of altruistic (and, to some degree, fatalistic) suicide.

Though there is strong evidence supporting some of Durkheim's more specific theses, particularly the fact that a lack of integration puts people at risk of mental, physical, and social health problems (Umberson and Montez 2010; Thoits 2011), others have not been as fortunate. For instance, anomic suicide has received inconsistent empirical verification (Breault 1994) owing, in part, to the diversity of operationalization and Durkheim's own ambiguous conceptualization of the differences between regulation and integration (Johnson 1965; Pope 1976). Furthermore, until recently, altruistic and fatalistic suicides have received almost no empirical consideration (Pescosolido 1994; Davies and Neal 2000; Leenaars 2004; Stack 2004; 
Abrutyn and Mueller 2016). One reason for the dearth of research on the excessive types of suicide stems from sociology's tendency to adhere closely to a literal interpretation of a classic. As such, Durkheim argued that both of these types were artifacts of mechanical societies, where underindividuation reigned supreme and a duty to self-sacrifice for the greater good could be imposed and enforced. Still, he pointed to military suicides as one common example, though his interpretation of the high military suicide rate is open to debate as well (Braswell and Kushner 2012). Besides these problems, Durkheim's model has been criticized on the grounds that its overemphasis of aggregate-level patterns prevents sociology from dealing with questions central to sociology's contribution to prevention: e.g., how do individuals come to choose suicide (Douglas 1967; Kral 1994; Abrutyn and Mueller 2014b). Thus, there are a fair number of legitimate critiques of the conventional Durkheimian model, such that modifying it is an important step forward. We turn now to the case of sati to further illustrate Durkheim's weaknesses while also suggesting how to move forward.

\section{SATI}

History. Sati is often used in two ways: to refer to the practice or ritual of selfimmolation or as a noun to describe the widow who self-immolates. In India, the term sati has always meant 'virtuous, chaste and faithful bride' (Barbagli 2015:192). Though Durkheim associates sati with very ancient India, the first mention of sati appears rather late in Hindu texts (Garzilli 1997). Indeed, while Vedic and Brahmanic aspects of Hinduism date back to at least the early first millennium BCE, sati's earliest appearance coincides with the decline in women's status in northern India in the $4^{\text {th }}$ century CE (ibid.; also, Barbagli 2015). Evidence appears to support the argument that it first became institutionalized within the Kshatriya or princely/warrior caste, but soon spread around $1000 \mathrm{CE}$ to the Brahmins and, eventually, to the 
two lower castes (Thakur 1963). As Brahmins adopted the practice, whatever heroic/charismatic meaning sati had initially, gave way to a powerful set of religious meanings. And, with the adoption of the practice by the highest caste, a moral authority backing the prescribed social act led to a steady, but steep, growth of the practice across India.

By the decade between 1815 and 1826, the British government reported that 40 percent of sati was committed by Brahmins while 50 percent was committed by the lowest class, the Shudras (Yang 1989). While precise statistical evidence is spotty, some scholars have claimed that close to 100,000 widows died a year in the nineteenth century alone (ibid.), while more accurate estimates place this number at 33,000 or more a year meaning that over a million women self-immolated during British rule (Fisch 2006). This would amount to 1 suicide per 1000 women, and 2 per 100 women in regions that practiced sati the heaviest (Barbagli 2015). In 1907, for instance, the suicide ratio for women and men was significantly higher than in most European countries where men more frequently took their lives than women. Scholars generally assume the practice has been in decline since 1829 when the British passed laws against it that were maintained after Indian self-determination; a fact supported by the appearance of the more common gender ratios of men completing suicide more frequently than women. Today, sati appears to have become exceedingly rare. From 1943 to 1987, for instance, the official number of cases is listed at 28 with perhaps 2 other known cases (Weinberger-Thomas 1999). In 1988, the Indian government made it illegal to aid or abet sati, which has probably made it even rarer and more likely to be covered up.

Practice. Sati takes two forms: the more commonly known, sahagamana, in which the widow immolates herself on her husband's pyre and sahamarana in which she burns herself a short while after her husband's cremation. The ritual itself begins when the widow privately and 
then publicly declares her intention to self-immolate, a declaration that is irreversible lest she commit a sin graver than not declaring in the first place. Though local customs shape the preceding parts of the ritual, in essence, sati symbolizes a second marriage and thus the reader can imagine the dress, jewelry, procession, and so forth that accompany the ritual itself. In some cases, she would throw herself in the pyre, while in others the Brahmin was responsible for pushing her in. Similarly, family members play a role in many villages: in some places, they are authorized to beat her burning body with sticks to accelerate her death and avoid as much pain as possible, whereas in other places they circle the pyre to ensure the widow does not change her mind.

\section{Current Explanations}

Mental health. Before turning to the sociological explanation, it is worth noting that some scholars have suggested sati be understood within a medicalized frame (Inamdar, Oberfield and Darrell 1983; Bhugra and Bhui 2007). As opposed to social scientific explanations, these scholars search for intra-personal mechanisms that explain the mental illness causing women to choose suicide. This theory is not without its weaknesses. For example, psychiatric conclusions are based on speculation, as psychiatric evaluations of sati are non-existent (Colucci and Lester 2012). More critically, the organic nature of mental illness has been challenged in so far as (a) the labeling of an illness is culturally specific (Szasz 1960; Scheff 1966) and (b) a product of collective efforts to legitimate and monopolize certain diagnostic knowledge, psychiatric practices, and professional ethics (Pearlin, Avison and Fazio 2007). Indeed, one of the glaring weaknesses of the medicalized model of psychiatry is the fact that thousands of studies later, the biological basis or etiology of depression or anxiety, let alone more severe mental illnesses like schizophrenia, continues to be elusive (Horwitz 2002). If anything, the age of anxiety became the 
age of depression more so because of a shift in political and economic conditions, subsequent shifts in pharmaceutical marketing strategies, and the material and ideal interests of clinicians (Herzberg 2009; Wakefield 2013). Thus, whether Indian women suffer from the same sociallyconstructed mental illnesses is as open for debate as whether or not mental illnesses are to blame for the practice of sati. As such, Durkheim's theory, though limited in some ways, presents us with a more compelling explanation for sati upon which can be built a robust theory.

Durkheim's interpretation. In Suicide, Durkheim (1897 [1951]:219) classifies sati as an example of altruistic, in that this "barbarous practice" could only occur where people were underindividuated because of excessive integration. Altruistic suicides, both because of Durkheim's emphasis on the soldier's willingness to die to save his regiment - which, admittedly, are quite rare (Riemer 1998) — and because of the chosen label "altruism," tend to be understood as self-sacrificial (Stack 2004). Yet, concomitantly, Durkheim held sati up as an example of obligatory self-sacrifice. Durkheim resolves this apparent oxymoron by arguing that sati is not coerced in the physical sense, but rather motivated by positive emotions (ibid. 293; cf. Stack 2004; Abrutyn and Mueller 2014b): a Hindu widow joyously gives herself to her husband and to her village family. As will be shown shortly, not only does Durkheim's explanation not hold up under empirical scrutiny, but it also points to weaknesses in both of his excessive types of suicide and, thereby, the claim to a general theory of suicide. Consider the following dilemmas.

First, Durkheim's assertion that altruistic suicides were found only in traditional societies is problematic on two levels. Sati was not found in the earliest forms of Indian society, but evolved rather late (Barbagli 2015) and Durkheim unnecessarily delimits the possibility that excessive integration or regulation affects modern societies (Abrutyn and Mueller 2016; Mueller 
and Abrutyn 2016). Second, his choice in labels, altruism, calls into question whether or not any of his cases are self-sacrificial and, moreover, reinforces the idea that excessive integration or regulation are characteristics of long gone societies. Third, while Durkheim uses the term "obligatory" to specify the case of sati, he explicitly denies the role excessive regulation may play in many cases. Indeed, perhaps as Mueller and Abrutyn (2016) suggest, a four-fold typology is a nice heuristic device, but one that obfuscates how social forces shape suicide — that is, can one realistically imagine a collective or milieu in which high levels of integration are divorced from high levels of regulation (Bearman 1991; Pescosolido 1994; Abrutyn and Mueller 2016). Fourth, even if we set aside these criticisms, besides the high rates of military suicides in the nineteenth century, Durkheim provides little systematic evidence for altruistic suicide parallel to the use of multivariate analysis for egoistic and anomic.

Fifth, and relatedly, Durkheim cannot escape his own paradox, weakening the logic of altruism. On the one hand, Durkheim clearly sees integration (and regulation) as highly protective forces; a point that is obvious not just in Suicide, but in The Division of Labor, The Rules, and The Elementary Forms. Therefore, traditional societies only generated suicides in extreme conditions, as mechanical solidarity protected individuals. On the other hand, some of the most integrated places, like monasteries (Murray 1998) or the military (Kang and Bullman 2009), have been prone to severely high rates of suicide. Rather than confront what this social fact might mean, Durkheim explained these high rates as soldiers giving themselves up for their unit and their nation. Yet, when we delve more deeply into military suicide rates, we find this explanation untenable. Indeed, Braswell and Kushner (2012) posit, instead, that excessive integration is characterized by excessive regulation, and, at least in the case of the military, a hyper-masculine fatalistic culture is internalized by soldiers. Consequently, suicide is an easy 
reaction to the disjunction between intense, salient expectations and swift severe sanctions by real, imagined, and generalized others and an inability to externalize frustrations, trauma, anger, and shame for two reasons. Hyper-masculine culture is demarcated by proscriptions against helpseeking and highly cohesive structural environments facilitate internalization of grievances while tamping down complaints about the system, as the system and its members merge and thus complaints against the system is tantamount to complaints against intimate others and the self (Braswell and Kushner 2012). As such, under these conditions, failures are experienced as shameful, but shame must be by-passed as it is a painful emotion (Scheff 1997); and, because the highly structured environment reduces the ability to by-pass shame into outward rage (Gilligan 2003), soldiers repress the shame in favor of heightened depression or anxiety, increasing numbness, and eventual choice of suicide as a form of escaping the mortified self (Baumeister 1990; Abrutyn and Mueller 2014b).

These weaknesses of Durkheim's theory suggest collapsing altruistic and fatalistic suicides to extract the intersecting dynamics of integration and regulation (Bearman 1991), pushing away from the idea structure alone without culture explains anything (Mueller and Abrutyn 2016), and building a multi-level model in which integration and regulation do not cause suicide, but rather provide contextual factors that protect or make vulnerable populations to suicidality (Pescosolido 1994; Abrutyn and Mueller 2016) are necessary paths forward. By interrogating sati anew, these theoretical adjustments can be more clearly elucidated.

\section{TOWARDS A NEW INTERPRETATION}

\section{Step 1: Context Matters}


Culture matters. Culture matters for understanding suicide (Hjelmeland 2010; Colucci and Lester 2012). What suicide "means" to a group of people matters to the extent that it may proscribe or prescribe suicide when individuals belonging to a group (Niezen 2009; Kitanaka 2012; Stevenson 2014) or class of people (Canetto 1992; Zayas and Gulbas 2012; Mueller and Abrutyn 2016) experience certain things. Culture, however, is typically understood as an internalized, intra-personal force. Barbagli (2015:210), whose important work on the cultural history of suicide, exemplifies this in explaining sati by way of Indian culture, or what he defines as "the complex set of meanings and symbols, mindsets and beliefs, as well as classification systems shared by almost all the population of that country, which controlled the emotions by prescribing what should and should not be felt in a particular situation or following an event, and by suggesting how such feelings should be expressed" (cf. Hochschild 1979). Barbagli represents a major advance in the sociology of suicide, first because he takes seriously the implications of cultural dynamics and, second, as we shall see shortly, his consideration of emotions is essential to understanding sati, as well as suicide more generally.

To enhance the precision of this growing body of cultural studies within the sociology of suicide, I suggest a couple of fixes. First, despite Barbagli's assertion that Indian culture is shared by "almost all the population," sati, at least what reliable statistics we do have, is practiced by specific subgroups (as noted above, from 1815 to 1826, Brahmins and Shudras accounted for 90 percent of self-immolation), in specific regions (again, during that same time period 90 percent clustered in the region of Bengal, with tremendous variation within the region [Barbagli 2015:208]), and particular characteristics of women (older, either childless or past the early years of motherhood). In other words, Indian culture was not as widespread as Barbagli assumes, but rather highly localized in empirical reality and in its ability to shape suicidality. 
This conclusion finds support in Abrutyn and Mueller's (2016) argument that the more bounded a social unit or place is, the more coherent its culture. Drawing from Fine's (2012) work on idioculture — or the group culture and history that provides members with a sense of community - they argue that suicide is a local phenomenon as bounded groups are able to impose shared culture, reinforce it through extensive monitoring and swift sanctioning, and draw from a common well of memory. It is this latter part which is particularly important: Durkheim (1915 [1995]) noted that culture had a material base in that it was externalized in representations that were physically tangible. Sati, then, appears to cluster in some villages among some classes of people because the practice of sati remains real in external representations that allows it to adhere in the shared "mindsets and beliefs" of the majority of villagers.

Second, by shifting to local culture, Durkheim's integration and regulation take on new meaning. For instance, culture flows or circulates along the structural "conduits" that link people together, simultaneously giving meaning to the invisible structural reality that we must contend with and trickling down into the everyday reality of people by way of constraining the expression of feelings, thoughts, and behaviors (Hochschild 1979; Abrutyn 2014). Culture, then, is a force of integration in so far as it offers a collective a shared set of repertoires for acting, meanings for interpreting and anticipating action, and so forth. It is the local nature of cultural integration that give it teeth: where suicide is prescribed for certain classes of people, the act itself draws the group together in ritual and shared affectual response. Culture also provides a source or mechanism of regulation: it provides the evaluative content for making sense of emotions, thoughts, and behaviors. Both in terms of externalized representations that symbolize the group and its moral nature, as well as in the internalized meanings that shape identity and status processes. Thus, Barbagli is right in pushing us away from altruism and excessive 
integration, but makes the mistake of underestimating just how coerced sati is. In part, this is because coercion is often considered external to the actor, which means that only some cases exhibit clear physical and/or emotional coercion (Vijaykumar 2004). But, individuals also internalize these mechanisms and self-regulate. In a bounded environment, like an Indian village, the probability with which individuals will work hard to act as expected and avoid the pain of sanctioning, will be quite high. As such, excessive integration and regulation are quite coercive and, where cultural directives prescribing suicide exist, suicide can be self-coerced as much as coerced from without.

In sum, by bringing theories of group culture into dialogue with the sociology of suicide, the variation in where and who practices sati can begin to be better explained. It is also plausible to imagine that local culture helps explain why some indigenous communities are at risk of suicide clustering, while others that look structurally similar are not (Walls, Chapple and Johnson 2007; Stevenson 2014). Furthermore, employing this more precise frame breathes new life into Durkheim's structural model, as well as opens up opportunities to consider the way structure and culture play out at the micro-level. Hence, a comprehensive model of suicide must first re-engage Durkheim's structural arguments by injecting it with some new ideas. Following this, we turn to social psychological components like identity or status that provide the explanatory mechanisms for when, why, and how people choose suicide in relatively patterned ways (Mueller and Abrutyn 2015; Abrutyn and Mueller 2016).

Why structure still matters. How should we think about Durkheim and structure in the $21^{\text {st }}$ century? I suggest two moves: the first involves introducing power into the sociology of suicide, while the second considers the insights of structural symbolic interactionism (Stryker 1980). Turning to the first, Weber (1946) teaches us that worldviews — or, his terminology for a 
cultural configuration or idioculture — are shared by the material and ideal interests of those who adhere to them. Warriors, for instance, favor cultural proscriptions and prescriptions that emphasize glory, heroism, and material success in battle as they live by the edge of a sword. Additionally, Weber notes that, regardless of which came first, worldviews are accepted or tossed aside based on how well they do in legitimating structural inequities: "Good fortune thus wants to be 'legitimate' fortune" (ibid. 172). Unfair structural arrangements always need cultural mechanisms to sweeten the bitter pill. It is perhaps not surprising, then, that many scholars identify the emergence and spread of sati as proceeding closely behind the steady growth of severe gender inequality (Thakur 1963; Barbagli 2015). Before returning to this point, let's consider the evolution of the practice.

Indian society, especially classical Indian society, is notable for its sharply delineated class positions and its highly delimited social mobility (Dumont 1966). In one of the few exceptions in history, the priestly caste in India has long been higher in status and power than the warrior/princely caste. Conspicuous displays of wealth among the latter, such as the suicide of a widow or multiple widows, would be consistent with status contests in other cultures. Brahmins, being higher ranked than warriors, most likely adopted this practice as a means of ensuring their claim to higher rank, also displaying their wealth, and monopolizing another ritual and finding new sources of material support. Indeed, in a society where mobility is sharply limited, cultural innovations would be highly limited too. The near-beatification of the husband's legacy, deification of a sati, and the immense honor bestowed upon her surviving family appear to serve their ideal interests, while also reinforcing the Brahmin's claim to special status. Likewise, in a society in which mobility in life is nearly impossible, the adoption of the practice by the lowest class makes sense as well: if in life there is not clear path, then perhaps in death one can improve 
their next life and, if they are thinking of their surviving family, slightly improve their life in the present. In the former case, structural power and privilege drive the highest ranked to maintain their position, while in the latter case the same structural conditions drive the lowest rank to take extreme measures to ensure better position after reincarnation.

Now, we can return to the actual practice itself. Jason Manning's (2012) work on suicide as a form of social control reminds us, again, that power-differentials matter. Some suicides by those in subordinate positions, for instance, are protests against the powerful while others are aimed at punishing the living (cf. Fei 2010). Sati is neither of these, but it does stem from the structural position of women, the severe restrictions on mobility imposed by a caste system, and a cultural system that de-emphasizes inner-worldly action in favor of a future world where status may be better. Sati sometimes appears to be a willing sacrifice, but structural position influence what people deem as viable paths forward (Kemper 1978), and thus reduces widows' options or choices. Imagine the enormous pressure for both Brahmin and Shudra wives: you are the most subordinate person at the highest rank or lowest rank in a village, which means for the high status person, you have responsibilities to uphold your husband's and family's special claims to status, while for the lowest rank, you represent the one chance at "freeing" your family (up to seven generations [Vijayakumar 2004]) from the painful cycle of rebirth. There is nothing altruistic about these suicides; they are fatalistic, if anything. ${ }^{1}$ Thus, we need to think about power, excessive cultural and structural regulation, and the delimitation of choices. Suicide is not just an available, accessible, and applicable option; in some villages, for certain classes of

\footnotetext{
${ }^{1}$ The problem with fatalism revolves around many of the same problems as altruism: (a) Durkheim chose an unfortunate social psychological motive (escapism) as a label for an entire class of suicides instead of emphasizing the dynamics of excessive regulation, (b) he likewise deemed these rare, if not the rarest, type of suicide in history and modernity, and (c) he hastily wrote a single paragraph on fatalism, perhaps at the very end of the manuscript's preparation.
} 
women, it is the only option. Decision-making, however, involves micro-level processes, and by drawing from social psychological research, it becomes possible to more clearly elucidate the underlying causal mechanisms. That is, it is not enough to say culture prescribes sati or that power differentials reduce the options; we need to think about why some women would be more vulnerable than others.

\section{Step 2: Microdynamics and Motivation}

Identity and status dynamics. Symbolic interactionism teaches us that we learn to identify who we are (self) by way of the identities we learn to make and take in interaction and the status positions associated with these identities (Blumer 1969). Identities are the internalized meanings that organize feeling, thinking, and doing in recurring relationships with others, whether real (e.g., spouses), imagined (e.g., what a man might expect from any given woman and vice versa), or generalized (e.g., what the group expects from us) (Burke and Stets 2009); statuses are categoric distinctions (e.g., sex, race, education, occupation) made salient by their uneven access to desired resources (e.g., prestige) and shaped by beliefs about the types of performances, rewards, and influence that can be expected from individuals marked by one status characteristic or another (Ridgeway 2001). Both components of self are vehicles of structure and culture (Turner 2010). They are structured in so far as they are embedded in exogenous forces like demographics, intensive and/or extensive social ties, population and moral density, and so forth (Stryker 1980). Structure influences culture because society-wide stratification and patterned interactions influence (a) the meanings that shape identities and the beliefs that undergird status derive and (b) emotive, attitudinal, and behavioral rules (Abrutyn 
2014). For instance, Hindu women internalize identities rooted in gender and family that also have positional status expectations. When they perform, they are constrained by the situations that are structured in village life as much as by global and local cultural meanings. Global in that there is an "Indian" culture, no matter how general and abstract it is, and there is, importantly, a local culture embedded in the village, its collective memory, patterned behavioral repertoires, and the like.

What makes these villages different from, say, a U.S. city, is the relative size and boundedness. I would predict that the smaller the size and the denser the population, the greater the degree to which structural and cultural mechanisms of integration and regulation press against individuals. Not only is monitoring and sanctioning easier (Goffman 1961), but individual's commitment is typically extracted by delimiting the number of role-identities and status positions available such that a person derives the vast majority—if not all—of their sense of self-worth, efficacy, and honor from this identity (Coser 1974). Hindu women, in many villages, are not simply a "wife" and, after her husband's death, a "widow" in relationship to her spouse; she is, in a sense, married to the entire community who orients themselves to her as a wife and then a widow. Consequently, the pressure to conform is immense, and the very real probability of merging or fusing one's global self-concept with a specific role (Turner 1978) and the collective it is anchored in (Swann Jr. et al. 2012); role-merger presumes the internalization of existing culture, the transformation of others' expectations into feelings of moral obligation, and ultimately, the blurred boundaries between the self and others (including generalized others) (Summers-Effler 2004).

Culture and structure develop "teeth" by working on and through certain types of social psychological processes (cf. Turner 2010; Abrutyn 2014). To perform "widowhood" correctly, 
sati is the only behavioral repertoire available. Sati is "regarded as the model to which a virtuous, chaste and faithful wife should aspire...If a sati is happy, a widow is unhappy. While the former is loved, venerated and celebrated, the latter is hated, despised, avoided and abandoned" (Barbagli 2015:211). While some women undoubtedly are attracted to sati because they are venerated and, in some cases, deified, many women "choose" sati because it is the only real option available (ibid. 210). This is in fact largely a product of the lack of alternative ways of doing "widow," as in many villages women are only acknowledged when married and bearing children. To resist, then, meant not merely violating cherished Hindu religious norms, but inviting "the terror of anomie" (Berger 1969) or the total disintegration of the moorings that linked her to the real, imagined, and generalized others that made social reality possible. Her impurity, as Barbagli (2015:213) notes, would rob her of "a social identity [in so far as she could] continue to live in the house that had belonged to her spouse and family [but was treated] as an outsider." Put in to the concepts discussed above: not becoming sati threatened not only the role-identity of woman, but the very self to which it had merged. Moreover, widespread local status beliefs provide mythic and real examples to which women must aspire: a widow is expected to sati to maintain or elevate her husband, her own, and her family's status lest she destroy their status and bring great dishonor and shame to herself and local cultural expectations. Variation in available identities will influence the divergence or conformity of behavioral choices. I would predict, then, that villages where alternative scripts for performing "widowhood" are lacking, behaviors will coalesce around specific understandings of sati. Villages which provide multiple understandings for identities of womanhood, motherhood, and widowhood afford greater variation in gender performance and, consequently, fewer sati deaths. 
In addition to these social psychological processes, it is clear emotions are central to linking individuals to the local sociocultural context as well as in motivating behavior. Ultimately, I offer a set of principles that complements Barbagli's assertion that culture channels how we label emotions and come to express them. However, I would take his argument a step further and add precision: in the case of sati, I am suggesting shame is the tool by which suicide is conditioned, the painful emotion that women are motivated to avoid at all costs, and the bridge linking the meso-local structure and culture to the individual. Shame is both externalized as a weapon and internalized as mechanism of self-control.

Shame and its discontents. Despite Durkheim's best efforts, the influence psychology and psychiatry hold on the public's and, unfortunately, sociology's understanding of suicide continues to dominate, especially in terms of emotions. Thus, what we know or think we know disproportionately favors the use of clinical populations and an emphasis on sadness-based emotions and, more accurately, the cognitive appraisals of sadness like hopelessness or depression (Cavanaugh et al. 2003). Building off of mainly anecdotal evidence (Mokros 1995; Lester 1997; Kalafat and Lester 2000), Abrutyn and Mueller (2014b) proposed we re-interpret Durkheim's typology as having a shame-based axis that travels from anomie to fatalism to account for the role social forces play. Unlike these less systematic cases, sati provides us with an opportunity to consider how shame dynamics can condition an entire class of cases.

The notion that shame is intimately tied to identity, status, and therefore self appears as early as Cooley's work, but has become increasingly central to the social science of emotions (Tangney and Dearing 2002; Turner 2010). Unlike guilt which is focused on rules and behavior, shame is the feeling one gets when they believe others appraise their self as deficient, contemptuous, corrupt, and polluting (Lewis 2003); though we often avoid the term shame when 
talking of others' real or imagined disapproval of self (Cohen 2003), we very often reach for other words like mortified, humiliated, chagrined, ridiculed, dishonored, and embarrassed (Lewis 1971; Retzinger 1991). Shame is a moral emotion because it is a signal that the deficient self is (a) threatening a cherished social relationship and/or (b) to blame for the disintegration of that cherished relationship (Shott 1979; Scheff 1997). As such, it is an important emotion for selfregulation: maintaining appropriate performances, both in private and public, is motivated - in part- to avoid eliciting shame as much as to avoid destroying social relationships (Goffman 1967; Tangney and Dearing 2002; Turner 2007). Why avoid shame? The pain of shame has been found to be so intense that psychological defenses like repression and projection are common. Of course, like all emotions, the cultural codes guiding labeling and expression (or suppression) of the emotion are inequitably distributed (Ridgeway 2006). As would be expected, then, some folks, typically higher status individuals, deny shame and "by-pass" the emotion (but not the affectual experience), which often leads to expressions of other emotions-particularly anger (Retzinger 1991). Others, typically lower status individuals, experience what can best be called overt, undifferentiated shame — or, a chronic state of shame that is generally mislabeled using sad- and/or fear-based language, but which is intensely oppressive for the self (Scheff 1997). Not surprisingly, shame has been tied to a wide range of other-harm behaviors (Gilligan 2003) and self-harm behaviors (Scheff 1989), including suicidality (Abrutyn and Mueller 2014b).

What causes shame? Goffman (1967) pointed out that shame was closely related to our performances. When our activated identities are closely tied to our core understanding of self, we want to manage others' impressions through our performances such that they verify who we believe we are. A significant body of research underscores that when others fail to verify our sense of self, we feel painful negative emotions that motivate us to control our behavior with the 
goal of eliciting verification (Burke and Stets 2009; Turner 2010). Social status is also intimately tied to identity and our sense self and can generate feelings of shame when our status is threatened. The loss of status, or even just threats to it, is akin to a loss of honor, respect, and is often referred to in everyday parlance as "I am mortified" or "embarrassed" (cf. Lewis 1971). As such, humans pursue appropriate deference and control their behavior to maintain their status, if not improve it (Scheff 1988). Of course, these processes—both the maintenance of status and the appropriate performance of an identity - require a cultural understanding of what is good and what is socially expected. Indeed, we socially learn cultural meanings about identity, or what a "mother" or "widow" would feel, think, and do (Burke and Stets 2009) and about status, or what most (if not all) people would expect in terms of a mother or widow's performance, reward, esteem, and so forth (Ridgeway 2001). Most failures to perform an identity or our social status generate mild shame, and therefore, can be coped with (Lewis 1971). Additionally, people are often inclined to help us "save face" (Goffman 1967) when we commit mild transgression, further softening the pain of shame. Indeed, we are often authorized to use shame with significant others as a means of sustaining local status orders (e.g., gossip) and prevent upstarts. However, when the local structural and cultural environment is highly coherent and rigid and when the number of identities/status-positions is severely delimited, shame can be a major force facilitating and constraining social behavior. Research has demonstrated that having fewer identities, for example, means being vulnerable to great mental health problems because the self is dependent greatly on others' continued positive support (Thoits 1983); real or imagined failures that threaten this support causes immense shame that is difficult to manage, and may lead to a deadly negative feedback spiral in which shame is bypassed for anger, which incurs 
greater shame and greater anger, until either the shame is unbearable (Baumeister 1990) or the rage is externalized (Retzinger 1991).

Returning to our case of sati, then, we can illustrate the many paths of shame. First, in order for one to use shame or the threat of shame as motivation, the widow must be aware of the consequences for not choosing sati. The fact that she becomes persona non grata was discussed above, but when we refract this point through a sociology of shame, it gains greater weight. While isolation might be painful (Twenge, Catanese and Baumeister 2003), the sati faces far worse and untenable choices: leave the village, which is essentially a recipe for death as her only source of biological, mental, emotional, and social support are her husband's family, or continue to live with his family, but be treated as if invisible. "Widowhood represents a violation of the Hindu moral code... What was more, a woman who decided to outlive her husband stained herself...with even worse guilt because she was responsible for his death" (Barbagli 2015:212). Thus, upon her husband's death, the anticipation of living in chronic shame and isolation must be powerfully motivating. However, in her lifetime or in a village elder's lifetime, the rite of passage that publicly transforms the recently-widowed woman into this state of non-existence has been witnessed. The sati must prepare to

transition to a radically new and different status, a condition of sacrifice, mortification, penitence and social death. For the remainder of her life, she would have to sleep on the ground, eat once a day, never chew betel or be seen by others. [She was excluded] from all feasts and family celebrations [and d]espised by all...Therefore, if Indian women chose to ascend their husbands' pyres following their death, it was (above all) to escape the shame and humiliation of widowhood, as well as the hatred of others, including close friends and intimate women friends (Barbagli 2015:214, emphasis mine).

Garfinkel (1964) has described public degradation ceremonies as routinized rituals that transform a total identity (such as those Hindu women will occupy in small, bounded communities) into a 
much lower status position, bordering on "outsider." Thus, shame is the appraisal that selfimmolation will maintain her honor and glorify her husband and his family. Widowhood, conversely, is the severing of social relationships - to real others, to the group that gives her sustenance, and, depending on how devout she might be, to the generalized other as represented by a local deity; her structural position of subordination coupled with a culture that makes her expendable and threatens her with lower status in rebirth, makes the choice a non-choice.

However, shame also comes from outside. Because her suicide will free her husbands' family, for up to seven generations, from the dharma-samsara cycle ("the cycle of rebirth"), her husband's family—especially the men—have vested interests in seeing her follow through; not surprisingly, reports of emotional coercion are plentiful alongside threats of physical violence (Vijaykumar 2004). Again, for the lowest caste, brothers and uncles likely see her death as the only path to social mobility. While they cannot structurally move, her "deification" very likely brings immediate honor and status within the eyes of the village and, of course, in the next life, they are able to escape their current misfortune.

The Brahmin class has different reasons for shaming a widow. For one, other Brahmin males must maintain their power and privilege, and ensure that their wife will self-immolate, thus they have vested interests in making a fellow Brahmin's wife jump on the pyre. Additionally, they are responsible for upholding the harmonious link between the mundane and sacred world, and any potential disturbance could threaten the collective's material well-being as well as their legitimacy. Indeed, reports of women regretting the decision upon seeing the fire up close are coupled with reports of Brahmins physically coercing her to jump (Vijaykumar 2004; Barbagli 2015). Hence, while it is true that the decision to not commit suicide would be highly regulated by real actors, it is the force of the entire group and the mechanical nature of the 
cultural system that is what these women are powerless against. Therefore, it is apparent that not only is sati not altruistic, but it is a product of excessive structural and cultural regulation; that is, this type of suicide is the very definition of fatalism. With no value judgment necessary, we can conclude that women would likely not choose suicide if (a) it was not the model of virtue and chastity imposed by some villages, (b) the consequences for not choosing it did not end in shame, humiliation, the loss of social self, and, for all intents and purposes, the figurative death of self, and (c) the potential threat of real or imagined coercion was absent.

\section{FINAL THOUGHTS}

The paper above takes as its question: what can the Hindu practice of sati teach us about the ways in which structural and cultural conditions become consequential by way of social psychological processes influencing suicidal behavior? The conventional explanation comes in Durkheim's discussion of altruistic suicides, or the self-sacrifice of underindividuated or excessively integrated peoples like widows in so-called "primitive" societies. It was argued that Durkheim's interpretation was not only based on uneven data and nineteenth century Eurocentric beliefs, but that it has become increasingly apparent that his theoretical framework-especially in terms of how integration and regulation are related and whether or not they are causal forces or contextual conditions — cannot resist modification and elaboration if sociology is to continue to be relevant to suicidology. Hence, by examining sati, it was argued that a theoretical argument could be sketched that strengthens Durkheim's theory by making it more robust and generalizable.

As such, the following generic principles can be suggested. First, integration and regulation operate together, not as causal forces, but rather as contextual conditions. Excessive or 
exceedingly low levels of either/or produce the conditions facilitating vulnerabilities to not only suicide, but easily map onto extensive research on other mental health problems (Thoits 2011; Turner and Turner 2013; Perry 2014). Second, while structure matters, we must also pay attention to culture as it provides the underlying meanings of suicide that can increase the odds a person or class of persons become suicidal under aforementioned conditions or are protected against suicidality (Kral 1994; Mueller and Abrutyn 2016). Third, structure matters, but sometimes in ways Durkheim ignored; in the case of sati, and likely other types of suicides, power, power-differentials, and hierarchy delimit the types of options available, accessible, and applicable to subordinates. Fourth, identity and status matter as they are concomitantly interpersonal anchorages tying us to real others, groups, and even cultural systems as well as internalized cultural meanings and beliefs that prescribe or proscribe how we express emotions, thoughts, and behaviors (Turner 2010; Abrutyn 2014). Fifth, and finally, identity and status are inextricably tied to social emotions like pride and shame, and therefore, when thinking about patterns of suicidality, we must explore how structure and culture condition expectations and obligations, how identity and status performance are intimately driven by these expectations and obligations, and what types of options are available, accessible, and applicable for failing to meet these expectations and obligations. In short, these four principles need to be systematically applied to other cases, but it is clear that mass suicides, like the Jonestown cult suicide (Pescosolido 1994), clusters like those in high schools (Mueller and Abrutyn 2016; Mueller 2017) or in indigenous communities (Niezen 2009; Stevenson 2014), or more generic patterns like spikes in suicide rates during recessions or among divorcées all can benefit from a more indepth theoretical framework, as can sociology's contribution to prevention. 


\section{REFERENCES}

Abrutyn, Seth. 2014. Revisiting Institutionalism in Sociology: Putting the "Institution" Back in Institutional Analysis. New York: Routledge.

Abrutyn, Seth, and Anna S. Mueller. 2014a. "Are Suicidal Behaviors Contagious? Using Longitudinal Data to Examine Suicide Suggestion." American Sociological Review 79(2):211-227.

—. 2014b. "The Socioemotional Foundations of Suicide: A Microsociological View of Durkheim's Suicide." Sociological Theory 32(4):327-351.

—. 2016. "When Too Much Integration and Regulation Hurt: Re-envisioning Durkheim's Altruistic Suicide." Society and Mental Health 6(1):56-71.

Baller, Robert D., and Kelly K. Richardson. 2009. "The "Dark Side" of the Strength of Weak Ties: The Diffusion of Suicidal Thoughts." Journal of Health and Social Behavior 50(3):261-276.

Barbagli, Marzio. 2015. Farewell to the World: A History of Suicide. Cambridge: Polity. Baumeister, Ray. 1990. "Suicide as Escape From Self." Psychological Review 97(1):90-113. Bearman, Peter S. 1991. "The Social Structure of Suicide." Sociological Forum 6(3):501-524. Berger, Peter. 1969. The Sacred Canopy: Elements of a Sociological Theory of Religion. New York: Anchor Books.

Bhugra, D., and K. Bhui. 2007. Textbook of Cultural Psychiatry. Cambridge: Cambridge Univeristy Press.

Blumer, Herbert. 1969. Symbolic Interactionism: Perspective and Method. Berkeley: University of California Press.

Breault, K.D. 1994. "Was Durkheim Right? A Critical Survey of the Empirical Literature on Le Suicide." Pp. 11-29 in Emile Durkheim: Le Suicide 100 Years Later, edited by D. Lester. Philadelphia: The Charles Press.

Burke, Peter J., and Jan E. Stets. 2009. Identity Theory. New York: Oxford University Press.

Canetto, Silvia Sara. 1992. "She Died for Love and He for Glory: Gender Myths of Suicidal Behavior." Journal of Death and Dying 26(1):1-17.

Cavanaugh, J.T.O., A.J. Carson, M. Sharpe, and S.M. Lawrie. 2003. "Psychological Autopsy Studies of Suicide: A Systematic Review." Psychological Medicine 33:395-405.

Chua, Jocelyn Lim. 2014. In Pursuit of the Good Life: Aspiration and Suicide in Globalizing South India. Berkeley: University of California Press.

Collins, Randall. 1988. Theoretical Sociology. San Diego: Harcourt Brace Jovanovich, Publishers.

Colucci, Erminia, and David Lester (Eds.). 2012. Suicide and Culture. Cambridge, MA: Hogrefe.

Coser, Lewis. 1974. Greedy Institutions: Patterns of Undivided Commitment. New York: Free Press.

Davies, Christie, and Mark Neal. 2000. "Durkheim's Altruistic and Fatalistic." Pp. 36-52 in Durkheim's Suicide: A Century of Research and Debate, edited by W.S.F. Pickering and G. Walford. Long: Routledge.

Douglas, Jack D. 1967. The Social Meaning of Suicide. Princeton, NJ: Princeton University Press.

Dumont, Louis. 1966. Homo Hierarchicus. Chicago: University of Chicago Press. 
Durkheim, Emile. 1897 [1951]. Suicide: A Study in Sociology. Glencoe, Ill.,: Free Press. —. 1915 [1995]. The Elementary Forms of Religious Life. New York: Free Press.

Fei, Wu. 2010. Suicide and Justice: A Chinese Perspective. London: Routledge.

Fine, Gary Alan. 2012. "Group Culture and the Interaction Order: Local Sociology on the MesoLevel." Annual Review of Sociology 38:159-179.

Fisch, J. 2006. Burning Women: A Global History of Widow-Sacrifice from Ancient Times to the Present. London: Seagull Books.

Garfinkel, Harold. 1964. "Studies of the Routine Grounds of Everyday Activities." Social Problems 11(3):225-250.

Garzilli, E. 1997. "First Greek and Latin Documents on Sahagamana and Some Connected Problems." Indo-Iranian Journal 40(3):205-243.

Gilligan, James. 2003. "Shame, Guilt, and Violence." Social Research 70(4):1149-1180.

Goffman, Erving. 1961. Asylums: Essays on the Social Situation of Mental Patients and Other Inmates. Garden City, NY: Anchor Books.

-. 1967. Interaction Ritual: Essays on Face-to-Face Behavior. New York: Pantheon Books.

Herzberg, David. 2009. Happy Pills in America: From Miltown to Prozac. Baltimore: John Hopkins University Press.

Hjelmeland, Heidi. 2010. "Cultural Research in Suicidology: Challenges and Opportunities." Suicidology Online 1(1):34-52.

Hochschild, Arlie. 1979. "Emotion Work, Feeling Rules, and Social Structure." American Journal of Sociology 85(3):551-572.

Horwitz, Allan V. 2002. Creating Mental Illness. Chicago: University of Chicago.

Inamdar, Subhash C., Richard A. Oberfield, and Evelyn B. Darrell. 1983. "A Suicide by SelfImmolation: Psychosocial Perspectives." International Journal of Social Psychiatry 29:103-133.

Johnson, Barclay. 1965. "Durkheim's One Cause of Suicide." American Sociological Review 30(6):875-886.

Kalafat, John, and David Lester. 2000. "Shame and Suicide: A Case Study." Death Studies 24:157-162.

Kang, Han K., and Tim A. Bullman. 2009. "Is There an Epidemic of Suicides among Current and Former U.S. Military Personnel?" Annals of Epidemiology 19(10):757-760.

Kemper, Theodore. 1978. A Social Interactional Theory of Emotions. New York: John Wiley and Sons.

Kitanaka, Junko. 2012. Depression in Japan: Psychiatric Cures for a Society in Distress. Princeton: Princeton University Press.

Kral, Michael. 1994. "Suicide as Social Logic." Suicide and Life-Threatening Behavior 24(3):245-255.

Leenaars, Antoon. 2004. "Altrusitic Suicide: A Few Reflections." Archives of Suicide Research $8(1): 1-7$.

Lester, David. 1997. "The Role of Shame in Suicide." Suicide and Life-Threatening Behavior 27(4):352-361.

Lewis, Helen. 1971. Shame and Guilt in Neurosis. New York: International Universities Press. Lewis, Michael. 2003. "The Role of Self in Shame." Social Research 70(4):1181-1204.

Maimon, David, and Danielle C. Kuhl. 2008. "Social Control and Youth Suicidality: Situating Durkheim's Ideas in a Multilevel Framework." American Sociological Review 73(6):921943. 
Manning, Jason. 2012. "Suicide as Social Control." Sociological Forum 27(1):207-227.

Mokros, Hartmut B. 1995. "Suicide and Shame." American Behavioral Scientist 38(8):10911103.

Mueller, Anna S. 2017. "Does the Media Matter to Suicide?: Examining the Social Dynamics Surrounding Media Reporting on Suicide in a Suicide-Prone Community." Social Science and Medicine 180:152-159.

Mueller, Anna S., and Seth Abrutyn. 2015. "Suicidal Disclosures among Friends: Using Social Network Data to Understand Suicide Contagion." Journal of Health and Social Behavior 56(1):131-148.

—. 2016. "Adolescents under Pressure: A New Durkheimian Framework for Understanding Adolescent Suicide in a Cohesive Community." American Sociological Review 81(5):877-899.

Murray, Alexander. 1998. Suicide in the Middle Ages: The Violent Against Themselves. Oxford: Oxford University Press.

Niezen, Ronald. 2009. "Suicide as a Way of Belonging: Causes and Consequences of Cluster Suicides in Aboriginal Communities." Pp. 178-195 in Healing Traditions: The Mental Health of Aboriginal Peoples in Canada. Vancouver, BC: UBC Press.

Pearlin, Leonard J., William R. Avison, and Elena M. Fazio. 2007. "Sociology, Psychiatry, and the Production of Knowledge about Mental Illness and its Treatments." Pp. 33-53 in Mental Health, Social Mirrors, edited by W.R. Avinson, J.D. McLeod, and B.A. Pescosolido. New York: Springer.

Perry, Brea L. 2014. "Symptoms, Stigma, or Secondary Social Disruption: Three Mechanisms of Network Dynamics in Severe Mental Illness." Journal of Social and Personal Relationships 31(1):32-63.

Pescosolido, Bernice A. 1994. "Bringing Durkheim into the Twenty-First Century: A Network Approach to Unresolved Issues in the Sociology of Suicide." Pp. 264-293 in Emile Durkheim: Le Suicide 100 Years Later, edited by D. Lester. Philadelphia: The Charles Press.

Pescosolido, Bernice A., and Sharon Georgianna. 1989. "Durkheim, Suicide, and Religion: Toward a Network Theory of Suicide." American Sociological Review 54(1):33-48.

Pope, Whitney. 1976. Durkheim's Suicide: A Classic Analyzed. Chicago: University of Chicago Press.

Retzinger, Suzanne M. 1991. Violent Emotions: Shame and Rage in Marital Quarrels. Thousand Oaks, CA: Sage.

Ridgeway, Cecilia L. 2001. "Inequality, Status, and the Construction of Status Beliefs." in The Handbook of Sociological Theory, edited by J.H. Turner. New York: Kluwer/Plenum.

—. 2006. "Expectation States Theory and Emotion." Pp. 374-367 in Handbook of the Sociology of Emotions, edited by J.E. Stets and J.H. Turner. New York: Springer.

Riemer, J.W. 1998. "Durkheim's 'Heroic Suicide' in Military Combat." Armed Forces and Society 25(1):130-120.

Scheff, Thomas. 1966. Being Mentally Ill: A Sociological Theory. Chicago: Aldine Publishing Company.

—. 1988. "Shame and Conformity: The Deference Emotion System." American Sociological Review 53(3):395-406.

—. 1989. "Cognitive and Emotional Components of Anorexia: Re-Analysis of a Classic Case." Psychiatry 52(2):148-160. 
—. 1997. Emotions, the Social Bond, and Human Reality. Cambridge: Cambridge University Press.

Shott, Susan. 1979. "Emotion and Social Life: A Symbolic Interactionist Analysis." American Journal of Sociology 84(6):1317-1334.

Summers-Effler, Erika. 2004. "A Theory of the Self, Emotion, and Culture." Advances in Group Processes 21:273-308.

Stack, Steven. 2004. "Emile Durkheim and Altruistic Suicide." Archives of Suicide Research 8(1):9-22.

Stack, Steven, and Barbara Bowman. 2012. Suicide Movies: Social Patterns 1900-2009. Cambridge, MA: Hogrefe.

Stevenson, Lisa. 2014. Life Beside Itself: Imagining Care in the Canadian Arctic. Berkeley: University of California Press.

Stryker, Sheldon. 1980. Symbolic Interactionism: A Social Structural Version. Menlo Park, CA: The Benjamin Cummings Publishing Company.

Swann Jr., William B., Jolanda Jetten, Ángel Gómez, Harvey Whitehouse, and Brock Bastian. 2012. "When Group Members Gets Personal: A Theory of Identity Fusion."

Psychological Review 119(3):441-456.

Szasz, Thomas S. 1960. "The Myth of Mental Illness." American Psychologist 15:113-118.

Tangney, June Price, and Ronda L. Dearing. 2002. Shame and Guilt. New York: The Guilford.

Thakur, U. 1963. The History of Suicide in India: An Introduction. Delhi: Munshiram.

Thoits, Peggy A. 1983. "Multiple Identities and Psychological Well-Being: A Reformulation and Test of the Social Isolation Hypothesis." American Sociological Review 48(2):174-187.

—. 2011. "Mechanisms Linking Social Ties and Support to Physical and Mental Health." Journal of Health and Social Behavior 52(2):145-161.

Turner, J. Blake, and R. Jay Turner. 2013. "Social Relations, Social Integration, and Social Support." Pp. 341-356 in Handbook of the Sociology of Mental Health, edited by C.S. Aneshenel, J.C. Phelan, and A. Bierman. New York: Springer.

Turner, Jonathan H. 2007. Human Emotions: A Sociological Theory. New York: Routledge. -. 2010. Theoretical Principles of Sociology, Volume 2: Microdynamics. New York: Springer. Turner, Ralph H. 1978. "The Role and the Person." American Journal of Sociology 84(1):1-23.

Twenge, Jean M., Kathleen R. Catanese, and Ray Baumeister. 2003. "Social Exclusion and the Deconstructed State: Time Perception, Meaninglessness, Lethargy, Lack of Emotion, and Self-Awareness." Journal of Personality and Social Psychology 85(3):409-423.

Umberson, Debra, and Jennifer Karas Montez. 2010. "Social Relationships and Health: A Flashpoint for Health Policy." Journal of Health and Social Behavior 51(1 suppl):S54S66.

Vijaykumar, Lakshmi. 2004. "Altrusitic Suicide in India." Archives of Suicide Research 8(1):7380.

Wakefield, James. 2013. "DSSM-5: An Overview of Major Changes and Controversies." Clinical Social Work Journal 41(2):139-154.

Walls, Melissa L., Constance L. Chapple, and Kurt D. Johnson. 2007. "Strain, Emotion, and Suicide Among American Indian Youth." Deviant Behavior 28(3):219-246.

Weber, Max. 1946. "The Social Psychology of World Religions." Pp. 267-301 in From Max Weber: Essays in Sociology, edited by H. Gerth and C.W. Mills. New York: Oxford University Press. 
Weinberger-Thomas, Catherine. 1999. Ashes of Immortality: Widow-Burning in India. Chicago: University of California Press.

Wray, Matt, Cynthia Colen, and Bernice A. Pescosolido. 2011. "The Sociology of Suicide." Annual Review of Sociology 37:505-528.

Yang, A.A. 1989. "Whose Sati? Widow Burning in Early 19th Century India." Journal of Women's History 1(2):8-33.

Zayas, Luis H., and Lauren E. Gulbas. 2012. "Are Suicide Attempts by Young Latinas a Cultural Idiom of Distress." Transcultural Psychiatry 49(5):718-734. 